\title{
Determinants of Acute Diarrheal Disease Among Under-Five Children in Pawi Hospital, Northwest Ethiopia, 2013/14
}

\author{
Hayelom Brhanu ${ }^{1,2}$, Digsu Negese ${ }^{2}$, Mulat Gebrehiwot ${ }^{3}$ \\ ${ }^{1}$ Department of Environmental Health and Health Extension Service, Pawi Health Science College, Pawi, Ethiopia \\ ${ }^{2}$ Department of Epidemiology and Biostatistics, College of Medicine and Health Sciences, University of Gondar, Gondar, Ethiopia \\ ${ }^{3}$ Department of Environmental and Occupational Health and Safety, College of Medicine and Health Sciences, University of Gondar, Gondar, \\ Ethiopia
}

\section{Email address:}

khayelom12@gmail.com (H. Brhanu),digsuneg@gmail.com (D. Negesse), mulat.hiwot@gmail.com (M. Gebrehiwot)

\section{To cite this article:}

Hayelom Brhanu, Digsu Negese, Mulat Gebrehiwot. Determinants of Acute Diarrheal Disease Among Under-Five Children in Pawi Hospital, Northwest Ethiopia, 2013/14. American Journal of Pediatrics. Vol. 3, No. 6, 2017, pp. 68-75. doi: 10.11648/j.ajp.20170306.12

Received: January 24, 2017; Accepted: February 21, 2017; Published: November 3, 2017

\begin{abstract}
Background: Diarrhea is one of the leading causes of morbidity and mortality among under-five children nationally and globally. This study identified determinants of acute diarrheal disease among under-five children using hierarchical logistic regression. Objective: This study was conducted to identify determinants for hospitalization of children with acute diarrhea in Pawi Hospital, Benishangul Gumuz Region, Northwest Ethiopia, 2013/14. Methods: A hospital-based case-control study was performed on 148 cases and 442 controls. Data were collected using structured questionnaires. Both bivariate and hierarchical logistic multivariate analyses were carried out to identify the determinants of acute diarrheal. Results: Determinants for acute diarrheal disease were identified. Rural residence $[\mathrm{AOR}=6.8,95 \% \mathrm{CI}=(3.3,14)]$, mothers having a low education $[\mathrm{AOR}=4.0,95 \% \mathrm{CI}=(1.5,11.0)]$, living in a non-model households $[\mathrm{AOR}=2,95 \% \mathrm{CI}=(1.1,4.0)]$ were from socioeconomic variables. Improper child stool disposal $[\mathrm{AOR}=2.7,95 \% \mathrm{CI}=(1.5,4.8)]$, not treating water at home $[\mathrm{AOR}=2.5$, $95 \% \mathrm{CI}=(1.3,4.6)]$ were among the environmental sanitation factors. Child's age $6-11$ moths $[\mathrm{AOR}=3.8,95 \% \mathrm{CI}=(1.7,8.9)]$, bottle feeding $[\mathrm{AOR}=10,95 \% \mathrm{CI}=(4.6,21.9)]$, being malnourished $[\mathrm{AOR}=2.3,95 \% \mathrm{CI}=(1.3,3.91)]$, and maternal diarrhea $[\mathrm{AOR}=8.8,95 \% \mathrm{CI}=(4.0,19.0)]$ were determinants of acute diarrheal disease in under fives. Conclusions: Acute diarrhea is influenced by factors from all hierarchical levels. Therefore, Avoiding bottle feeding and interpersonal transmission, strengthening women's education, improving child nutrition; maximizing the health extension package model households and treating water at home are recommended with more emphasis on rural living children.
\end{abstract}

Keywords: Determinants, Acute Diarrhea, Children, Case-Control, Pawi Hospital, Ethiopia

\section{Background}

Infectious diarrhea remains one of the leading causes of childhood morbidity and mortality worldwide [1]. According to the World Health Organization (WHO) and United Nations Children Funds UNICEF, there are about two billion cases of diarrheal diseases worldwide every year [2]. Diarrhea kills more than 5,000 under-five children every day - more than AIDS, malaria, and measles combined, one in nine under-five child deaths are due to diarrhea [3]. While diarrheal disease occurs worldwide, 90 percent of diarrheal disease deaths in under-five children occur in developing countries [4].

Each child under five years of age experiences an average of three annual episodes of acute diarrhea. Globally in underfive age groups, acute diarrhea is the second leading cause of death (next to pneumonia), and both the incidence and the risk of mortality from diarrheal diseases are the greatest among under-five children in this age group. Other direct consequences of diarrhea in under-five children include malnutrition, growth faltering and impaired cognitive development in resource-limited countries [2].

In Ethiopia, diarrhea is the second cause of hospital admission and morbidity among children under 5 years next 
to pneumonia [5]. According to Ethiopian Demographic and Health Survey (EDHS) 2011, the prevalence of diarrhea among under-five children is $13 \%$. A high prevalence of diarrhea was observed among children residing in households that drink from unprotected wells (18\%), those residing in rural areas (14\%) and from Benshangul-Gumuz region. In this region, the prevalence of diarrhea is $23 \%$ with child mortality rate of 169 per 1,000 live births; both are the highest among regions in Ethiopia [6]. Diarrheal disease is the third cause of admission in patients at Pawi hospital [7].

Although, there are many determinants of diarrhea identified by different studies, the decision to include risk variables was based on statistical significance only but should also be determined through a hierarchical conceptual framework that includes various levels and maintains relationships [8]. This study thus aimed to assess the determinants of acute diarrhea among young children in Pawi hospital, Northwest Ethiopia.

\section{Methods}

A hospital-based case-control study was performed at Pawi General Hospital, from July to September, 2013.

\subsection{Study Area and Setting}

The study was conducted at Pawi hospital from July to September 2013. Pawi General Hospital, the only hospital in Metekel zone, serves a population of 597,970, and provides care to approximately 4,270 children every year; 37 of the 129 beds in the hospital are allocated for children. Metekel zone is found in Benishangul-Gumuz region. It is the largest zones among the three zones found in the region with an area of 26,272 square kilometers, located $570 \mathrm{Kms}$ Northwest of Addis Ababa, (the Ethiopian capital) and $390 \mathrm{Kms}$ from Assosa (the Regional State capital). The most common health problems of children in Metekel zone as well as in the region are communicable diseases like, malaria, pneumonia, and diarrhea.

\subsection{Study Population}

All mothers/caregivers with children aged less than five years enrolled from July to September 2013 at Pawi hospital OPD/pediatrics ward in Metekel zone were included in this study. Children in the case group who took any antibiotics in the previous two weeks were excluded.

\subsection{Sample Size and Sampling Procedure}

A total of 618 under five children were selected and 10\% non response rate was used to compute the sample size. This sample size was calculated by using EpiInfo 3.5.3 considering the following assumptions: $95 \%$ confidence level; $90 \%$ power; $1: 3$ case to control ratio; at least 2 the odds ratio to be detected; and $57.7 \%$ proportion of controls with exposure of bottle feeding from previous study in Ethiopia [9]. The cases studied where children with acute diarrhea on the pediatric ward/POPD of Pawi hospital coming for treatment from July to September, 2013. The controls were recruited from children on the same ward/OPD during the same period for causes other than diarrheal infection. A questionnaire was filled from mothers/caregivers in the OPD and inpatient pediatric ward. The first eligible case was selected for interview mother/caregiver at OPD after the child was diagnosed. But if the selected child had referred to inpatient, mothers/caregivers were interviewed in the inpatient when their child was received appropriate drug and/or supportive therapy.

\subsection{Data Collection and Quality}

A structured questionnaire was prepared based on reviewed literature. The common language in Metekel zone is Amharic. The questionnaire was prepared in English, then translated to Amharic, and back translated to English to maintain consistency. Mothers/caregivers were interviewed in the OPD/inpatient pediatrics ward on separate room. Three nurse data collectors and a supervisor were recruited and trained for 1 day on the technique of the interview and data collection. Pre-test was done in the hospital one week before the actual data collection in order to sort out language barriers and contextual differences on 28 mothers.

\subsection{Operational Definitions}

Diarrhea was defined as the passage of three or more liquid stools within a 24-hour period. Acute diarrhea defined as having diarrhea for less than 14 days.

\subsection{Data Collection and Management}

Data on socio-demographic, environmental sanitation and child care behavioral related variables were collected using a structured data collection format. The format was pretested at Pawi hospital one week before the actual data collection on 28 participant mothers and improved accordingly. Data were collected by a public nurse who works at the under-five OPD/inpatient pediatrics wardof the hospital. Data were then checked, coded and entered in to EpiInfo version 3.5.3 and analyzed by SPSS version 20.0. Most of the variables were fitted to the bivariate logistic regression. Then all variables having $\mathrm{p}$ value $\leq 0.2$ in the bivariate analysis were further entered into multivariate hierarchical logistic regression model. Variables reaching the p-values 0.15 were kept in the subsequent multivariate model and in the final model variables having $\mathrm{p}$ value $<0.05$ were taken as significant determinants. Crude and adjusted odds ratios with their $95 \%$ confidence intervals were calculated.

\subsection{Ethical Considerations}

Ethical clearance was obtained from Institutional Review Board of the University of Gondar. Permission letter was obtained from Pawi hospital administration. Volunteer informed consent from individual mothers was obtained. Names and personal identifiers of mothers were not included in the study. 


\section{Results}

Socio-demographic characteristics of the study participants

A total of 618 mothers/caretakers of under-five children (148 cases and 442 controls) with a response rate of $95.5 \%$ were included in the analysis. One hundred forty three (96.6\%) cases and 426 (96.4\%) controls had their mothers as caretakers.

One hundred thirty six (92\%) cases, and $260(58.8 \%)$ controls were from rural areas. Ninety seven $(65.5 \%)$ cases and $155(35.1 \%)$ controls were born from mothers with no formal education. Thirty two $(21.6 \%)$ of cases and $69(15.6 \%)$ of controls were from families graduated of the health extension package. Orthodox religion followers accounted $58.1 \%$ of the cases and $60.4 \%$ of the controls.

Ethnically, 99 (67\%) of cases and $270(61 \%)$ controls were Amhara. Married participants accounted $92.6 \%$ and $93.7 \%$ among the cases and controls respectively. Sixty six (44.6\%) of the cases and half (50.7\%) controls mother's were farmers by occupation. Economic status, 79 (53.4\%) cases and 206 (46.6\%) control were from the family of middle income (Table 1$)$.

Table 1. Selected socioeconomic and demographic characteristics among under-five children (cases=148, controls=442) in Pawi Hospital, Northwest Ethiopia, 2013.

\begin{tabular}{|c|c|c|c|}
\hline Variable & Category & Cases (\%) & Controls (\%) \\
\hline \multirow{2}{*}{ Residence } & Urban & $12(8.1)$ & $182(41.2)$ \\
\hline & Rural & $136(91.9)$ & $260(58.8)$ \\
\hline \multirow{3}{*}{ Maternal education } & No formal education & $97(65.5)$ & $155(35.1)$ \\
\hline & Primary $(1-8)$ & $39(26.4)$ & $209(48.3)$ \\
\hline & Secondary and above $(9+)$ & $12(8.1)$ & $78(17.6)$ \\
\hline \multirow{7}{*}{ Ethnicity } & Gumuz & $5(3.4)$ & $16(3.6)$ \\
\hline & Shinasha & $3(2.0)$ & $10(2.3)$ \\
\hline & Agew & $16(10.8)$ & $68(15.4)$ \\
\hline & Amhara & $99(66.9)$ & $270(61.1)$ \\
\hline & Kembata & $17(11.5)$ & $33(7.5)$ \\
\hline & Hadiya & $3(2.0)$ & $28(6.3)$ \\
\hline & Others* & $5(3.4)$ & $17(3.8)$ \\
\hline \multirow{2}{*}{ Religion } & Orthodox & $86(58.1)$ & $267(60.4)$ \\
\hline & Muslim & $39(26.4)$ & $107(24.2)$ \\
\hline \multirow{2}{*}{ Family Size } & $\leq 5$ & $91(61.5)$ & $243(55.0)$ \\
\hline & $>5$ & $57(38.5)$ & $199(45.0)$ \\
\hline Maternal age mean $( \pm \mathrm{SD})$ & $27.1( \pm 5.56)$ & $26.8( \pm 5.2)$ & $27.2( \pm 5.7)$ \\
\hline \multirow{4}{*}{ Marital status of mother/caretaker } & Married & $137(92.6)$ & $414(93.7)$ \\
\hline & Single & $0(0)$ & $5(1.1)$ \\
\hline & Divorced & $6(4.0)$ & $16(3.6)$ \\
\hline & Widowed & $5(3.4)$ & $7(1.6)$ \\
\hline \multirow{4}{*}{ Occupation of mother/caretaker } & Housewife & $45(30.4)$ & $117(26.5)$ \\
\hline & Farmer & $66(44.6)$ & $224(50.7)$ \\
\hline & Private work & $26(17.6)$ & $65(14.7)$ \\
\hline & Gov't employee & $11(7.4)$ & $36(8.1)$ \\
\hline \multirow{3}{*}{ Family's monthly income } & Low (250-999) & $39(26.4)$ & $115(26)$ \\
\hline & Middle $(1,000-2,999)$ & $79(53.4)$ & 206(46.6) \\
\hline & High $(3,000-8,500)$ & $30(20.2)$ & $121(27.4)$ \\
\hline
\end{tabular}

*Tigrie, Welayta, Berta **Catholic, No religion

Environmental sanitation characteristics

One hundred twenty four (83.8\%) cases and 399 (90.3\%) controls were from a family with a latrine. Among the 523 latrines, 120 (96.8\%) cases and 295 (74\%) controls had traditional pit latrine; $98(79 \%)$ cases and $368(92.2 \%)$ controls was owned privately.

Eighty three $(56.1 \%)$ case's child stool disposing improperly; whereas $320(72.4 \%)$ controls of child stool disposal in a latrine. More than half $(53.2 \%)$ controls families were disposed refuse properly but $91(61.5 \%)$ cases used the open field as solid waste disposal method.

Improved source of drinking water was used by 94 (63.5\%) cases and $374(84.6 \%)$ controls household. Ninety nine $(70 \%)$ cases did not have sources of household water in their compound, but more than halve $(56 \%)$ of the controls had in their compound. One hundred two $(68.9 \%)$ of cases and 231 $(52.3 \%)$ controls household families consume less than twenty liters per capita per day of water. one hundred seventeen $(79 \%)$ cases and $266(60 \%)$ of controls family did not use a home based water treatment method (Table 2).

Table 2. Environmental sanitation characteristics among under-five children (cases=148, controls=442) in Pawi Hospital, Northwest Ethiopia, 2013.

\begin{tabular}{llll}
\hline Variable & Category & Cases (\%) & Controls (\%) \\
\hline Latrine availability & Yes & 124(83.8) & $399(90.3)$ \\
& No & $24(16.2)$ & $43(9.7)$ \\
\hline
\end{tabular}




\begin{tabular}{|c|c|c|c|}
\hline Variable & Category & Cases (\%) & Controls (\%) \\
\hline \multirow[t]{2}{*}{ Latrine Type $(\mathrm{n}=523)$} & Traditional Pit Latrine & $120(96.8)$ & $295(73.9)$ \\
\hline & Ventilated Improved latrine & $4(3.2)$ & $104(26.1)$ \\
\hline \multirow{2}{*}{ Latrine ownership (n=523) } & Private & $98(79.0)$ & $368(92.2)$ \\
\hline & Shared & $26(21.0)$ & $31(7.8)$ \\
\hline \multirow{2}{*}{ Child stool disposal } & In latrine & $65(44)$ & $320(72.4)$ \\
\hline & Not In latrine & $83(56)$ & $122(27.6)$ \\
\hline \multirow{2}{*}{ Refuse disposal method } & Open field & $91(61.5)$ & $207(46.8)$ \\
\hline & Pit/Burning/Garbage bin & $57(38.5)$ & $235(53.2)$ \\
\hline \multirow{2}{*}{ Source of water in the compound } & Yes & $49(33.1)$ & $247(55.9)$ \\
\hline & No & $99(66.9)$ & $195(44.1)$ \\
\hline \multirow{2}{*}{ Type of water collection container } & Pot & $12(8.1)$ & $25(5.7)$ \\
\hline & Jerry can & $136(91.9)$ & $417(94.3)$ \\
\hline \multirow{2}{*}{ Source of drinking water } & Improved & $94(63.5)$ & $374(84.6)$ \\
\hline & Unimproved & $54(36.5)$ & $68(15.4)$ \\
\hline \multirow{2}{*}{ Daily water consumption } & $\leq 20$ litre per capita per person & $102(68.9)$ & $231(52.3)$ \\
\hline & $>20$ litre per capita per person & $46(30.1)$ & $211(47.7)$ \\
\hline Distance to water & $\leq 15$ minute & $129(87)$ & $401(90.7)$ \\
\hline Source & $>15$ minute & $19(13)$ & $41(9.3)$ \\
\hline \multirow{2}{*}{ Drinking water treatment at home } & yes & $31(21)$ & $176(39.8)$ \\
\hline & No & $117(79)$ & $266(60.2)$ \\
\hline \multirow{2}{*}{ Shied to domestic animals } & yes & $26(17.6)$ & $17(3.8)$ \\
\hline & No & $122(82.4)$ & $425(96.2)$ \\
\hline
\end{tabular}

Child care and behavior related characteristics

Half (50\%) cases and $260(59 \%)$ controls were males; the mean $( \pm \mathrm{SD})$ age of children was $21( \pm 14.8)$ months cases and $23( \pm 15)$ the controls. Eighty four $(56.8 \%)$ cases and $213(48 \%)$ controls were born in a health facility. Thirty six $(24.3 \%)$ of cases and 21 (4.8\%) of controls were on bottle feeding.
Nutritional status of the child was assessed by weight for height $\mathrm{Z}$ score. Accordingly, 47 (31.8\%) cases and 81 (18.3\%) controls were wasted. One hundred six $(71.6 \%)$ cases and $344(77.8 \%)$ controls were measles vaccinated. Forty three $(48.6 \%)$ cases and $12(2.7 \%)$ controls had reported with maternal history of diarrhea (Table 3).

Table 3. Child care and behavior characteristics of under-five years children (cases=148, controls=442) in Pawi Hospital, Northwest Ethiopia, 2013.

\begin{tabular}{|c|c|c|c|}
\hline Variable & Category & Cases (\%) & Controls (\%) \\
\hline \multirow{2}{*}{ Sex of child } & Male & $74(50.0)$ & $260(58.8)$ \\
\hline & Female & $74(50.0)$ & $182(41.2)$ \\
\hline \multirow{4}{*}{ Age of child (months) } & $<6$ & $21(14.2)$ & $49(11.1)$ \\
\hline & $6-11$ & $24(16.2)$ & $79(17.9)$ \\
\hline & $12-24$ & $53(35.8)$ & $119(26.9)$ \\
\hline & $25+$ & $50(33.8)$ & $195(44.1)$ \\
\hline \multirow{2}{*}{ Place of birth of child } & Health facility & $85(57.4)$ & $212(48.0)$ \\
\hline & Home & $63(42.6)$ & $230(52.0)$ \\
\hline \multirow{4}{*}{ Birth order } & $1^{\text {st }}$ & $45(30.4)$ & $149(33.7)$ \\
\hline & $2^{\text {nd }}$ & $46(31.1)$ & $105(23.8)$ \\
\hline & $3^{\text {rd }}$ & $21(14.2)$ & $72(16.3)$ \\
\hline & $4^{\text {th }}+$ & $36(24.3)$ & $116(26.2)$ \\
\hline \multirow{3}{*}{ Breastfeeding Status } & Exclusive breastfeeding & $31(20.9)$ & $68(15.4)$ \\
\hline & Mixed breastfeeding & $92(62.2)$ & $241(54.5)$ \\
\hline & No breastfeeding & $25(16.9)$ & $133(30.1)$ \\
\hline \multirow{2}{*}{ Bottle feeding } & Yes & $36(24.3)$ & $21(4.8)$ \\
\hline & No & $112(75.7)$ & $425(96.2)$ \\
\hline \multirow{3}{*}{ Duration of breast feeding } & $<6$ months & $70(47.3)$ & $176(39.8)$ \\
\hline & $6-23$ months & $57(38.5)$ & $191(43.2)$ \\
\hline & $24+$ months & $21(14.2)$ & $75(17.0)$ \\
\hline \multirow{2}{*}{ Vaccination status for $>9$ month $(n=499)$} & Fully vaccinated & $93(74.4)$ & $317(84.8)$ \\
\hline & Not Fully vaccinated & $32(25.6)$ & $57(15.2)$ \\
\hline \multirow{2}{*}{ Measles } & Yes & $106(71.6)$ & $344(77.8)$ \\
\hline & No & $42(28.4)$ & $98(22.2)$ \\
\hline \multirow{2}{*}{ Maternal history of diarrheal in previous 2 wks } & Yes & $43(29.1)$ & $12(2.7)$ \\
\hline & No & $105(70.9)$ & $430(97.3)$ \\
\hline \multirow[t]{2}{*}{ Height for Age Z score } & Normal & $92(62.2)$ & $276(62.4)$ \\
\hline & Stunted & $56(37.8)$ & $166(37.6)$ \\
\hline \multirow[t]{2}{*}{ Weight for Age Z score } & Normal & $74(50.0)$ & 281(63.6) \\
\hline & Underweight & $74(50.0)$ & 161(36.4) \\
\hline \multirow{2}{*}{ Weight for Height $Z$ score } & Normal & 101(68.2) & $361(81.7)$ \\
\hline & Wasted & $47(31.8)$ & $81(18.3)$ \\
\hline \multirow{2}{*}{ Hand wash practice of mother } & Good & $4(2.7)$ & $25(5.7)$ \\
\hline & Poor & 144(97.3) & $417(94.3)$ \\
\hline
\end{tabular}


Determinants of acute diarrheal disease among under-five children; Overall relationships (Model description)

Socio-demographic, environmental sanitation, and childcare and behavioral variables explain acute diarrheal disease among under-five children but better explain the outcome in model 3. Therefore the outcome of the final model (model 3) alone was used and interpreted (Table 4).

Table 4. Model describing the hierarchical logistic regression analysis on the determinants of acute diarrheal disease among under-five children in Pawi hospital, Ethiopia, 2013.

\begin{tabular}{lll}
\hline Model & Block x ${ }^{2}(\mathbf{p}$-value) & $\begin{array}{l}\text { Hosmer-Lemeshow's goodness } \\
\text { of-fit-test (p-value) }\end{array}$ \\
\hline Model 1 & $110.92(<0.001)$ & 0.387 \\
Model 2 & $144.80(<0.001)$ & 0.495 \\
Model 3 & $240.91(<0.001)$ & 0.973 \\
\hline
\end{tabular}

Mode 1: socio-demographic variables, Model 2: sociodemographic + environmental sanitation variables Model 3: socio-demographic + environmental sanitation + child care and behavioral variables.

Determinants of acute diarrheal disease among under-five children

(Hierarchical logistic regression multivariate final results)

From the crude analysis, residence, educational status of the mother/caretaker, family size, the family's monthly income and being model household in health extension package were variables showed significant association with diarrheal disease. Among the environmental sanitation variables: latrine availability, solid waste disposal method, child stool disposal, daily consumption of water per capita per liter and home based water treatment had significantly increased the odds of childhood diarrhea. Age of children, bottle feeding, vaccination of measles, hand wash practice of the mother, weight for age and height, maternal hand wash practice and history of diarrhea were identified as significant risk factors of childhood diarrhea morbidity in the bivariate analysis.

In the multivariate analysis of the final model, children born from no formal educated mothers' had more than four times higher odds of having diarrhea as compare to children born from mothers attained secondary and above [AOR = $4.13,95 \% \mathrm{CI}=(1.54,11.06)]$. The odds of diarrhea in children from rural areas were more than six-fold higher as compared children from urban areas $[\mathrm{AOR}=6.84,95 \% \mathrm{CI}=$ (3.26, 14.33)].

From the environmental sanitation variables entered in the second block of the analysis, water treating at home and improper child stool disposal remained significant. Accordingly the odds of developing diarrhea in children didn't use treated drinking water at home were 2.4 times higher compared to children used home treated drinking water $[\mathrm{AOR}=2.46,95 \% \mathrm{CI}=(1.32,4.57)]$. The odds of having diarrhea in children disposed their stool improperly were more than two times higher to children disposed their stool in a latrine $[\mathrm{AOR}=2.72,95 \% \mathrm{CI}=(1.54,4.81)]$.

Bottle feeding, being age 6-11 months, wasted children and history of maternal diarrhea was determinant factors among the child care and behavior in the final model. The odds of having diarrhea in children on bottle feeding were ten times higher to children who were not used $[\mathrm{AOR}=10,95 \%$ $\mathrm{CI}=(4.56,21.94)]$. The odd of having diarrhea in children born from a mothers with a history of diarrhea were more than eight times higher relative to children born from diarrhea free mothers in the preceding two weeks [AOR= $8.81,95 \% \mathrm{CI}=(4.04,19.20)]$. The odds of having diarrhea in children being in the age group 6-11 months were more than two times higher to children being in the age of 25 months and above $[\mathrm{AOR}=3.85,95 \% \mathrm{CI}=(1.67,8.86)]$. The odds of having diarrhea among wasted children were two-fold higher than the normal children $[\mathrm{AOR}=2.25,95 \% \mathrm{CI}=(1.30,3.91)]$ (Table 5).

Table 5. Summary of the hierarchical logistic regression analysis of socioeconomic, environmental sanitation, and child care and behavior factors on the morbidity of acute childhood diarrhea in Pawi hospital, Metekel zone, Northwest Ethiopia, 2013.

\begin{tabular}{|c|c|c|c|c|c|}
\hline Variable & Category & Cases & Control & $\operatorname{COR}(95 \%$ C. I) & $\operatorname{AOR}(95 \%$ C. I) \\
\hline \multicolumn{6}{|l|}{ Socio-demography variables } \\
\hline \multirow{2}{*}{ Family residence* } & Urban & 12 & 182 & 1.00 & 1.00 \\
\hline & Rural & 136 & 260 & $7.9(4.3,14.8)$ & $6.80(3.26,14.30)$ \\
\hline \multirow{3}{*}{ Educational status of mother* } & No Education & 97 & 155 & $4.1(2.1,7.8)$ & $4.13(1.5,11.06)$ \\
\hline & Primary & 39 & 209 & $1.2(0.6,2.4)$ & $1.08(0.40,2.78)$ \\
\hline & Secondary and above & 12 & 78 & 1.00 & 1.00 \\
\hline \multirow{3}{*}{ Monthly income } & Minimum & 39 & 115 & $1.4(0.8,2.3)$ & $1.60(0.79,3.38)$ \\
\hline & Middle & 79 & 206 & $1.5(0.96,2.5)$ & $1.56(0.80,2.90)$ \\
\hline & High & 30 & 121 & 1.00 & 1.00 \\
\hline \multirow{2}{*}{ HEP Model* } & Yes & 32 & 69 & 1.00 & 1.00 \\
\hline & No & 116 & 373 & $0.7(0.9,2.38)$ & $2.06(1.07,3.98)$ \\
\hline \multirow{2}{*}{ Family size } & $\leq 5$ & 91 & 243 & 1.00 & 1.00 \\
\hline & $>5$ & 57 & 199 & $0.8(0.9,1.9)$ & $1.40(0.81,2.45)$ \\
\hline \multicolumn{6}{|c|}{ Environmental sanitation variables } \\
\hline \multirow{2}{*}{ Latrine availability } & Yes & 124 & 399 & 1.00 & 1.00 \\
\hline & No & 24 & 43 & $1.8(0.3,0.95)$ & $1.86(0.84,4.14)$ \\
\hline \multirow{2}{*}{ Child stool disposal * } & In latrine & 65 & 320 & 1.00 & 1.00 \\
\hline & Not in latrine & 83 & 122 & $3.4(3,5)$ & $2.72(1.54,4.81)$ \\
\hline \multirow{2}{*}{ Water percapita consumption } & $\leq 20$ liter & 102 & 231 & $2(1.4,3.0)$ & $1.74(0.97,3.10)$ \\
\hline & $>20$ liter & 46 & 211 & 1.00 & 1.00 \\
\hline
\end{tabular}




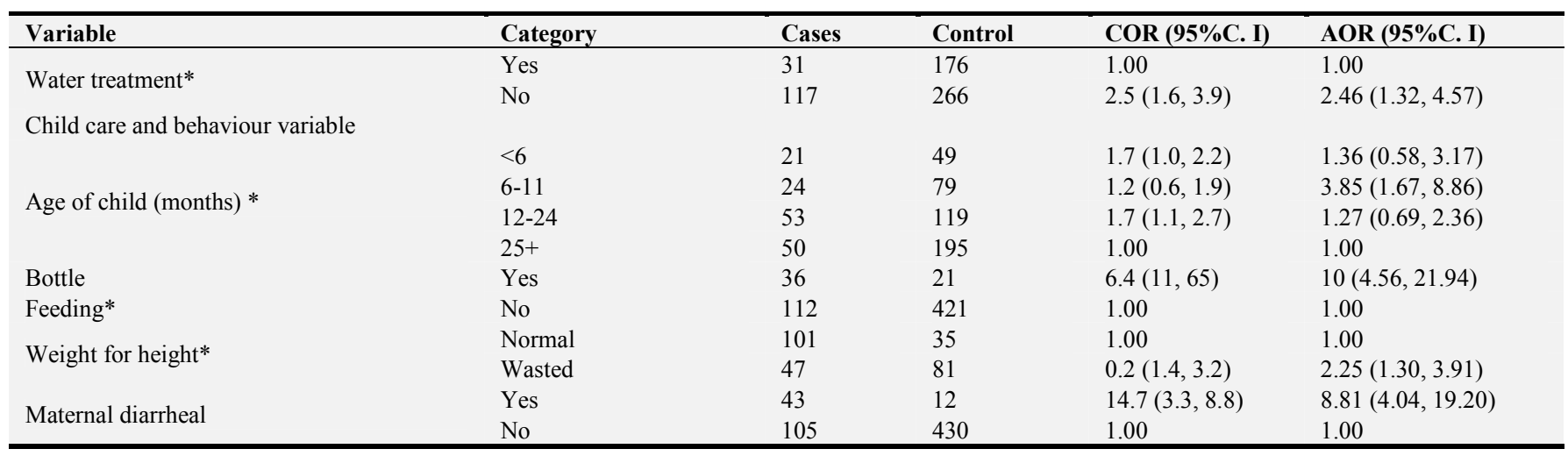

* Significant at $\mathrm{p}<0.05$

\section{Discussion}

The aim of this study was identifying determinants of acute diarrhea among under-five children and the major determinants were maternal education, residence, and HEP model household; child stool disposal, drinking water treatment at home, maternal history of diarrhea, child age, bottle feeding and malnutrition.

Children living in the rural areas were more likely to have diarrhea compared to those in the urban areas. This result is consistent with the finding in Eritrea [10]. The variation in residence may encompass different elements, ranging from the health seeking behavior of mothers to the availability of health services and clean household environment and water services. People in urban areas will have better health seeking behavior; they may have good access to health services and clean and safe water. Urban children were considerably more likely to have been taken for advice or treatment for diarrhea than rural children (54 percent versus 29 percent) [6].

Children from mothers with no formal educationwere significantly exposed to diarrhea than children from mothers of higher-level education. This finding is similar to the result obtained from another study in Ghana and Nigeria, where the morbidity of diarrhea varies according to education of mothers which was relatively high among children of mothers with no education [11-19]. Educated mothers will have better health seeking behavior and they will practice good child caring like taking appropriate action when feeding their offspring's and during refusal disposal [11].

Being a model in HEP showed significant association with the morbidity of diarrhea in children. This might due to increased training and high follow up from the health extension workers for the graduated households. Model households might have better understanding related to the health of children and mothers.

Using drinking water treated at home was a predictor of diarrheal morbidity. This may be due to collect water is liable for contamination during collection, transportation and storage which may in turn increase risk of diarrheal diseases. This finding is in agreement with study in Kenya and Ethiopia [20-22], but contradicts other previous studies in Ethiopia [23]. This difference might be attributed to the various methods of home based water treatment, and difference in the overall sanitation of the environment.

Improper child stool disposal was associated with acute diarrhea, this was consistent with different previous studies in Ethiopia [21, 24]. This is an important implication that the mere presence of latrine facility does not have a great contribution to prevention of excreta-related disease but it is the proper utilization that had a vital importance.

It is well documented that maternal child care and hygiene practices have important impacts on the morbidity of diarrhea in children [22]. In this study, maternal history of diarrheal disease was associated with diarrheal morbidity in under-five children. This might be explained by the fact that maternal morbidity considered as a sign of disease exposure in a family. This is so because mothers are food handlers of the family and they are usually the main child care providers [10, 22]. In addition, the care of the child may be compromised if the mother herself is sick. This finding was observed in Congo and Ethiopia, where maternal diarrheal morbidity was associated with a two-fold and five-fold increase in the odds of diarrheal disease in children respectively. Mother's exposure to diarrhea may also indicate poor hygienic practice in the household that results in disease incidence for the children $[19,25,26]$. A significant association was observed between bottle feeding and diarrheal morbidity. Similar findings were observed in different areas of Ethiopia $[9,21$, 27]. The age of the child was shown a statistically significant association with the occurrence of childhood diarrhea, which is consistent with many studies in sub-Sahara countries; like in Eritrea, Ghana and Ethiopia [10, 16, 19]. According to study conducted in Eritrea, the risk was highest at age segments of 6-11 months and least at less than six months and 24 months and above. The low risk of diarrhea at the age group less than six months could be due to the protective effect of breast milk, inborn immunity and less exposure to unhygienic condition in the first six months of the child. On the other hand, the morbidity of diarrhea in the 6-11 month peaks when the child has lost inborn immunity, weaning practices, and exposed to different types of infections from eating food prepared with unclean water and food handler, and in unhealthy environments. At this age also, infants are either crawling or walking and, as such, can easily pick dirt or other unhygienic objects if left with less care and more attention is not given. 
Nutritional status of the child was a determinant of childhood diarrhea. Wasting or thinness is indicated in most cases a recent and severe process of weight loss, which is often associated with acute starvation and/or severe disease [28]. This might be due to loss of nutrients in stools, and lack or malabsorption of nutrients during diarrhea and decrease in food intake both due to loss of appetite and restrictive feeding practices [29]. The finding was in line with studies done in Ethiopia, Peru, and South America but inconsistent with a study done in India. Nutritional status was not statistically associated with the occurrence of childhood diarrheal illness, rather with duration of diarrheal illness [29-31].

\section{Limitations}

Selection of controls in the hospital led to a limitation that the experience of the controls may not accurately represent the exposure distribution in the population from which the cases were derived. However, the majority of the controls were identified at OPD level, with diseases common to other healthy children, suggesting that the selection bias of controls in our study might be low.

Some determinants were difficult to quantify, like economic level of the study subjects. Sometimes, they did not know their income exactly. Observation may be needed for some of the variables like sanitation, hygiene and water related practices at household level. However, it was impossible in the context of limited time and manpower. Some diseases in the control groups like pneumonia might have common shared risk factors with acute diarrhea.

\section{Conclusion}

Acute diarrheal disease in children age less than five is influenced by factors from all hierarchical levels. An indication of a single factor may not reduce the problem of acute diarrheal diseases in under-five children.

This study identified under-five children from no formal maternal education, living in rural areas, not graduated in health extension package, improper child stool disposal, not using home based water treatment, maternal history of diarrhea in the previous two weeks of interviews, being in the age segments of 6-11 month, bottle feeding and being wasted as determinant factors of acute childhood diarrhea. In addition risk factors like graduation status of households in health extension package were different from previous results.

\section{Authors' Contributions}

$\mathrm{HB}, \mathrm{DN}$ and MG participated in all steps of the study from its inception to the write up. All authors have reviewed and approved the submission of the manuscript.

\section{Acknowledgements}

We are very grateful to Pawi Health Science College, for financial support of this study.

\section{References}

[1] Boschi-Pinto C, Velebitb L, Shibuyac K. Estimating child mortality due to diarrhoea in developing countries. Bulletin of the World Health Organization May 30, 2008; 86: (9): 710-7.

[2] Farthing M, Salam M, Lindberg G, Dite P, Khalif I, SalazarLindo E, et al. Acute diarrhea in adults and children: a global perspective. World Gastroenterology Organisation Global Guidelines. World Gastroenterology Organisation. 2012 February.

[3] CDC. Diarrhea: Common Illness, Global Killer. Centers for Disease Control and Prevention, 2009.

[4] PATH. Diarrheal disease: solutions to defeat a global killer. PATH, May, 2009.

[5] FMoH. Health and Health Related Indicators. Addis Abeba: Federal ministry of Health policy planning Directorate; 2011/12.

[6] Central Statistical Agency Addis Ababa E. Ethiopia Demographic and Health Survey 2011. In: Central Statistical Agency Addis Ababa EIIC, Maryland, USA., editor. Addis Ababa, Ethiopia: Central Statistical Agency 2012.

[7] Pawi-Hospital. Woreda-based health sector plan, hospital annual plan. pawe: pawi hospital; 2012/13.

[8] Victora CG, Huttly SR, Fuchs SC. The role of conceptual frameworks in epidemiological analysis: a hierarchical approach. Int J Epidemiol. 1997; 26: 224-27.

[9] Wondwossen B. A stepwise regression analysis on under-five diarrhoael morbidity prevalence in Nekemte town, western Ethiopia: maternal care giving and hygiene behavioral determinants. East Afr J Public Health. 2008 Dec; 5 (3): 193-8.

[10] Woldemicael G. Diarrhoeal morbidity among young children in Eritrea: environmental and socioeconomic determinants. J Health Popul Nutr. 2001 Jun; 19 (2): 83-90.

[11] Yilgwan C. S, Okolo S. N. Prevalence of diarrhea disease and risk factors in Jos University Teaching Hospital, Nigeria. Ann Afr Med. 2012 Oct-Dec; 11 (4): 217-21.

[12] Yilgwan C. S, Yilgwan G, Abok II. Domestic water sourcing and the risk of diarrhoea: a cross-sectional survey of a periurban community in Jos, Nigeria. Niger J Med. 2010 Jul-Sep; 19 (3): $271-4$

[13] Senyonga R, Muwonge R, Twebaze FBN, Mutyabule R. Determinants of acute diarrhea in children aged $0-5$ years in Uganda. East African Medical Journal 2009 November; 86 (11): 513-9.

[14] Mohammed S, Tilahun M, Tamiru D. Morbidity and Associated Factors of Diarrheal Diseases Among Under Five Children in Arba-Minch District, Southern Ethiopia. Science Journal of Public Health. 2013 2012; 1 (2): 102-6.

[15] Shikur M, Marelign T, Dessalegn T. Morbidity and associated factors of diarrheal diseases among under five children in Arba-Minch district, Southern Ethiopia, 2012. Science Journal of Public Health. 2013 June 10, 20131 (2): 102-6.

[16] Oadi KO, Kuitunen M. Childhood diarrheal morbidity in the Accra Metropolitan Area, Ghana: Socio-economic, environmental and behavioral risk determinants. J Health Pop Dev Countries. 2005: 33-46. 
[17] Dikassa L, Mock N, Magnani R, Rice J, Abdoh A, Mercer D. Maternal behavioral risk factors for severe childhood diarrheal disease in Kinshasa, Zaire.. Int J Epidemiol. 1993 (22): 327-33.

[18] Cesar GV, Bryce J, Fontaine O, Monasch R. Reducing deaths from diarrhoea through oral rehydration therapy. Bull World Health Organization 2000 (78): 1246-55.

[19] Dessalegn M, Kumie A, W T. Predictors of under-five childhood diarrhea: Mecha District, West Gojam, Ethiopia. Ethiop J Health Dev. 2011; 25 (3): 190-200.

[20] Fewtrell L, Kaufmann B, Kay D, Enanoria W, Haller L, Colford J. Water, sanitation, and hygiene interventions to reduce diarrhoea in less developed countries. A systematic review and meta-analysis.. Lancet Infectious Disease. 2005 (5): 42-52.

[21] Wanzahun G, Bezatu M. Environmental Factors Associated with Acute Diarrhea among Children Under Five Years of Age in Derashe District, Southern Ethiopia. Science Journal of public Healh. 2013; 1 (3): 119-24.

[22] Tarekegn M, Enquselassie F. A case control study on determinants of diarrheal morbidity among under-five children in Wolaita Soddo Town, Southern Ethiopia. School of Public Health, Addis Ababa University;. Ethiop J Health Dev. 2012; 26 (2).

[23] Andualem A. Assessment of the impact of latrine utilization on diarrhoeal diseases in the rural community of Hulet Ejju Enessie Woreda, East Gojjam Zone, Amhara Region. Ethiopian. Journal of Health Development. 2010; 24 (3): 11018.
[24] Girma R, Wondwossen B, Bishaw D, Tefera B. Environmental determinants of diarrhoea among under-five children in Nekemte Town, western Ethiopia.. Ethiopia Jornal of Health Sciences. 2007; 18 (2): 39-44.

[25] Mock N, Sellers T, Abdoh A, Franklin R. Socioeconomic, environmental, demographic and behavioral factors associated with the occurrence of diarrhea in young children.. Soc Sci Med. 1993; 36 (6): 807-16.

[26] Ezra M GE. Breastfeeding, birth intervals and child survival: Analysis of the 1997 community and family survey data in southern Ethiopia.. Ethiop J Health Dev. 2002; 16 (1): 41-51.

[27] Ghosh S, Sengupta PG, Mondal SK, Banu MK, Gupta DN, Sircar BK. Risk behavioural practices of rural mothers as determinants of childhood diarrhoea.. J Commun Dis. 1997; 29 (1): 7-14.

[28] WHO. World Health Organization global database on child growth and malnutrition. Geneva: World Health Organization 1997.

[29] Anand K, Sundaram KR, Lobo J, Kapoor SK. Are diarrheal incidence and malnutrition related in under five children? a longitudinal study in an area of poor sanitary conditions. Indianpediatrics. 1994 Aug; 31 (8): 943-8.

[30] Tomiso A. Prevalence and determinants of childhood diarrhea among graduated households, in rural area of shebedino district, southern Ethiopia. 2013.

[31] Destaw B. Prevalence and associated factors for diarrhea disease among under-five children in Dabat district, northwest Ethiopia. 2013. 